Original Article

\title{
Comorbidity and it's Impact on COVID-19 Affected Patients in COVID-19 Dedicated Hospital of Bangladesh
}

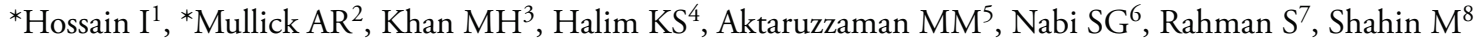

\begin{abstract}
The Wuhan City of China evidenced unknown aetiology pneumonia cases at the end of December 2019. On 7 January 2020, the causative agent was identified as a novel coronavirus (2019-nCoV), currently referred to as SARS-CoV-2, and coronavirus disease as COVID-19. Older adults and people of any age who have underlying medical conditions, such as hypertension and diabetes, have shown worse prognosis. The aim of this study to evaluate the risk of serious adverse outcomes in patients with COVID-19 by stratifying the comorbidity status. We conducted a retro-prospective study of 405 patients admitted into the Mugda Medical College and Hospital, Dhaka,Bangladesh. Among 405 cases, mean age was 46.33 years. About 216 (53.3\%) patients were male. Almost 322 (79.5\%) patients were managed inside Dhaka city. The most common symptom was fever on or after hospitalisation (71.9\%). Of the 405 cases the prevalence of specific comorbidities was: hypertension $(n=141,34.8 \%)$, other cardiovascular diseases $(n=42$, 10.4\%) cerebrovascular diseases $(n=7,1.7 \%)$, diabetes
\end{abstract}

1. *Dr Irin Hossain, Assistant Professor, Department of Occupational and Environmental Health $(\mathrm{OEH})$, National Institute of Preventive and Social Medicine (NIPSOM), Dhaka. E-mail: irin.hossain @gmail.com

2. *Dr Ashekur Rahman Mullick, Field Supervisor, NIPSOM, Dhaka

3. Prof. Dr. Manzurul Haque Khan, Consultant, CDC, DGHS, Dhaka

4. Prof. Dr. Kazi Shafiqul Halim, Professor \& Head, Department of Epidemiology, NIPSOM, Dhaka

5. Dr M M Aktaruzzaman, Assistant Director, Dhaka Medical College and Hospital, Dhaka

6. Dr Shah Golam Nabi, Principal, Mugda Medical College, Dhaka

7. Dr. Md. Shafiur Rahman, Assistant Professor and Head, Department of OEH, NIPSOM, Dhaka

8. Dr Md. Shahin, Medical Officer (OSD), DGHS, Dhaka

*For Correcpondence $(n=140,34.6 \%), \operatorname{COPD}(n=4,1.0 \%)$, chronic kidney diseases $(n=65,16.0 \%)$, malignancy $(n=4,1.0 \%)$ and asthma ( $n=51,12.6 \%)$. Overall, 307 (75.8\%) patients discharged alive during the time frame of this study. 98(24.2\%) patients died, 63 (15.6\%) were admitted to the ICU and 16 (4.0\%) received invasive ventilation. Patients with comorbidities should take all necessary precautions to avoid getting infected with SARS CoV-2, as they usually have the worst prognosis. There is a need for a global public health campaign to raise awareness, on reducing the burden of these comorbidity illnesses causing deaths in COVID-19-infected patients.

Keywords: Co-morbidity, impact of COVID-19, COVID-19 pandemic

\section{INTRODUCTION}

The Wuhan City of China evidenced unknown aetiology pneumonia cases at the end of December 2019 ${ }^{1-10}$. On 7 January 2020, the causative agent was identified as a novel coronavirus $(2019-\mathrm{nCoV})^{3-5}$, currently referredto as SARS-CoV-2 $2^{4-6}$, and coronavirus disease as COVID-19 $9^{4-10}$. The disease over runentire China ${ }^{2-5}$ and surpassed international borders inno time ${ }^{2.3}$, extending the world tally to $>27$ million confirmed cases and $>0.9$ million deaths ${ }^{11-13}$.

Older adults and people of any age who have underlying medical conditions, such as hypertension and diabetes, have shown worse prognosis ${ }^{14}$. Diabetic patients have increased morbidity and mortality rates and have been linked to more hospitalization and intensive care unit (ICU) admissions ${ }^{14-17}$. People with chronic obstructive pulmonary disease (COPD) or any respiratory illnesses are also at higher risk for severe illness from COVID-19 ${ }^{18}$. The risk of contracting COVID-19 in patients with COPD is found to be four fold higher than patientswithout $\mathrm{COPD}^{18-20}$. There are significant differences between Bangladesh, China and the US in population demographics, ${ }^{21}$ smoking rates, ${ }^{22}$ and prevalence of comorbidities. ${ }^{23-25}$ In this study we tried to evaluate the risk of serious adverse outcomes in patients with COVID-19 by stratifying the comorbiditystatus. 


\section{METHODS AND MATERIALS}

\section{Study Population, Setting, and Design}

We conducted a retro-prospective study of 405 patients admitted into the Mugda Medical College and Hospital, Dhaka, Bangladesh. All patients who were diagnosed with COVID-19 according to WHO interim guidance ${ }^{26}$ were screened, and those who died or were discharged between May 1, 2020 and June 31, 2020, were included in this study.

\section{Data collection}

Epidemiological, demographic, clinical and outcome data were obtained from patient charts and the hospitals'

admission records using a structured questionnaire which was adopted from Novel Coronavirus (COVID-19 Rapid Version) by Global COVID-19 Clinical Platform which was previously used for same purpose in United Kingdom ${ }^{27}$ and China ${ }^{9}$. All data were collected by expert physicians and public health specialist.

\section{Statistical analysis}

We used the $\chi 2$ test, or Fisher's exact test to compare differences between survivors and non- survivors where appropriate and also for severe and non-severe patients. The level of significance was set at 0.05 . SPSS 26.0 was used to analyse the data.

\section{RESULT}

Table I : Demographic findings, comorbidities and related sigh-symptoms of patients on admission

\begin{tabular}{|l|l|c|c|c|}
\hline Variables & & Severe $(\mathrm{n}=197)$ & Non-severe $(\mathrm{n}=208)$ & p value \\
\hline \multirow{3}{*}{ Gender } & Female & $89(47.1 \%)$ & $100(52.9 \%)$ & 0.559 \\
\cline { 2 - 5 } & Male & $108(50.0 \%)$ & $108(50.0 \%)$ & \\
\cline { 2 - 5 } & & $30(40.5 \%)$ & $44(59.5 \%)$ & 0.280 \\
\cline { 2 - 5 } & Chronic Cardiac Disease & $21(50 \%)$ & $21(50 \%)$ & 0.980 \\
\hline \multirow{2}{*}{ Comorbidity } & HTNoker & $83(58.9 \%)$ & $58(41.1 \%)$ & 0.011 \\
\cline { 2 - 5 } & Asthma & $22(43.1 \%)$ & $29(56.9 \%)$ & 0.552 \\
\cline { 2 - 5 } & CKD & $41(63.1 \%)$ & $24(36.9 \%)$ & 0.035 \\
\cline { 2 - 5 } & Others & $89(63.6 \%)$ & $51(36.4 \%)$ & 0.000 \\
\hline Fever & & $13(13.3 \%)$ & $11(4.3 \%)$ & 0.184 \\
\hline Cough & & $137(47.1 \%)$ & $154(52.9 \%)$ & 0.315 \\
\hline Cough with sputum & & $118(48.2 \%)$ & $127(51.8 \%)$ & 0.595 \\
\hline Sore throat & & $23(42.6 \%)$ & $31(57.4 \%)$ & 0.531 \\
\hline Runny nose & & $83(56.8 \%)$ & $63(43.2 \%)$ & 0.021 \\
\hline Wheezing & & $17(63.0 \%)$ & $10(37.0 \%)$ & 0.270 \\
\hline Chest pain & & $33(62.3 \%)$ & $20(37.7 \%)$ & 0.033 \\
\hline Muscle ache & & $35(43.2 \%)$ & $46(56.8 \%)$ & 0.333 \\
\hline Joint pain & & $22(45.8 \%)$ & $26(54.2 \%)$ & 0.545 \\
\hline Fatigue & & $93(52.5 \%)$ & $84(47.5 \%)$ & 0.166 \\
\hline Shortness of breath & & $125(59.0 \%)$ & $87(41.0 \%)$ & 0.000 \\
\hline Inability to walk & & $67(74.4 \%)$ & $23(25.6 \%)$ & 0.000 \\
\hline Chest in-drawing & & $55(85.9 \%)$ & $9(14.1 \%)$ & 0.000 \\
\hline Headache & & $23(37.1 \%)$ & $39(62.9 \%)$ & 0.142 \\
\hline Altered consciousness & & $32(75.0 \%)$ & $13(25.0 \%)$ & 0.000 \\
\hline Abdominal pain & & $24(60.0 \%)$ & 0.191 \\
\hline Nausea/Vomiting & & $53(59.6 \%)$ & 0.128 \\
\hline Diarrhoea & & $31(49.2 \%)$ & 0.585 \\
\hline
\end{tabular}


Table I shws taht among 405 cases, mean age was 46.33 years. About $216(53.3 \%)$ patients were male. Almost 322(79.5\%) patients were managed inside Dhaka city. Themost common symptom was fever on or after hospitalisation (71.9\%), followed by dry cough (60.5\%). Shortness of breath $(52.3 \%)$, fatigue $(43.7 \%)$ and sore throat $(36.0 \%)$ were also found. Of the 405 cases the prevalence of specific comorbidities was: hypertension $(\mathrm{n}=141,34.8 \%)$, other cardiovascular diseases $(\mathrm{n}=42$, $10.4 \%)$ cerebrovascular diseases $(n=7,1.7 \%)$, diabetes $(\mathrm{n}=140,34.6 \%)$, COPD $(\mathrm{n}=4,1.0 \%)$, chronic kidney diseases $(n=65,16.0 \%)$, malignancy $(n=4,1.0 \%)$ and asthma ( $\mathrm{n}=51,12.6 \%)$. Hypertension was seen more commonly in severe cases than in non-severe cases (58.9\% versus $41.1 \%)$ followed by chronic kidney disease $(63.1 \%$ versus $36.9 \%)$, diabetes $(63.6 \%$ versus $36.4 \%)$. In case of on treatment complications the pattern of distribution was sore throat $(56.8 \%$ versus $43.2 \%)$, fatigue $(52.5 \%$ versus $47.5 \%)$, shortness of breath $(59.0 \% \%$ versus $41.0 \%)$, diarrhoea $(50.8 \%$ versus $49.2 \%$ ), and alteration of consciousness (75.0\% versus $25.0 \%)$.

Table II shows that overall, 307 (75.8\%) patients discharged alive during the time frame of this study. 98 (24.2\%) patients died, 63 (15.6\%) were admitted to the ICU and 16 (4.0\%) received invasive ventilation. Hypertension was seen more commonly in patients who has been discharged alive than in decease case $(61.0 \%$ versus $39.0 \%)$ followed by asthma $(78.4 \%$ versus $21.6 \%$ ), chronic kidney disease $55.4 \%$ versus $44.6 \%$ ), diabetes $(60.7 \%$ versus $39.3 \%)$.

\section{DISCUSSION}

In our study circulatory and endocrine comorbidities were common among patients with COVID-19. Patients with at least one comorbidity, or even more so, were associated with severe health status. These findings have provided further objective evidence, with a large sample size and extensive coverage of the geographic regions across Bangladesh, to take into account baseline comorbid diseases in the comprehensive risk assessment of prognosis among patients with COVID-19 on hospital admission. Overall, our findings have rebounded the recently published studies in terms of the commonness of comorbidities in patients with COVID-19 $9^{27-32}$. Despite considerable variations in the proportion in individual studies due to the limited sample size and the region where patients were managed, circulatory diseases (including hypertension and coronary heart diseases) remained the most common category of comorbidity ${ }^{27-30}$. Apart from circulatory diseases, endocrine diseases such as diabetes were also common in patients with COVID-1929,30. Not with standing the commonness of circulatory and endocrine comorbidities, patients with COVID-19 rarely reported having comorbid respiratory diseases (particularly COPD $)^{30}$. Consistent with recent reports ${ }^{27-30}$, the percentage of patients with comorbid renal disease and malignancy was relatively low. Our findings have therefore added to the existing literature on the spectrum of comorbidities in patients with COVID-19 based on the larger sample sizes and representativeness of the whole patient population in Bangladesh.

A number of existing literature reports have documented the escalated risks of poorer clinical outcomes in patients with avian influenza ${ }^{31-35}$, SARS-CoV ${ }^{36}$ and MERS-Co

Table II : Relationship between comorbidity and health outcome

\begin{tabular}{|l|l|c|c|c|}
\hline Variables & & Survivor $(\mathrm{n}=307)$ & Non-survivor (n=98) & p value \\
\hline \multirow{3}{*}{ Comorbidity } & Chronic Cardiac Disease & $26(61.9 \%)$ & $16(38.1 \%)$ & 0.070 \\
& HTN & $86(61.0 \%)$ & $55(39.0 \%)$ & 0.000 \\
\cline { 2 - 5 } & Asthma & $40(78.4 \%)$ & $11(21.6 \%)$ & 0.823 \\
\cline { 2 - 5 } & CKD & $36(55.4 \%)$ & $29(44.6 \%)$ & 0.000 \\
\cline { 2 - 5 } & DM & $85(60.7 \%)$ & $55(39.3 \%)$ & 0.000 \\
\hline
\end{tabular}


Vinfections ${ }^{37-45}$. The most common comorbidities associated with poorer prognosis included diabetes ${ }^{44,46}$, hypertension $^{47}$, respiratory diseases ${ }^{32,46}$, cardiac diseases ${ }^{32,40}$, pregnancy $^{35}$, renal diseases ${ }^{31,36}$ and malignancy ${ }^{33}$. Our findings suggested that, similar with other severe acute respiratory outbreaks, comorbidities such as COPD, diabetes, hypertension and malignancy predisposed to adverse clinical outcomes in patients with COVID-19. The strength of association between different comorbidities and the prognosis, however, was less consistent when compared with the literature reports ${ }^{28,35,40,47}$. For instance, the risk between cardiac diseases and poor clinical outcomes of influenza, SARS-CoV or MERS-CoV infections was inconclusive $28,40,46$. Except for diabetes, no other comorbidities were identified to be the predictors of poor clinical outcomes in patients with MERS-CoV infections ${ }^{42}$.

Our findings suggested that patients with comorbidities had greater disease severity compared with those without. Furthermore, a greater number of comorbidities correlated with greater disease severity of COVID-19. The proper triage of patients should be implemented by carefully inquiring about the medical history because this will help identify patients who would be more likely to develop serious adverse outcomes of COVID-19. Moreover, better protection should be given to the patients with COIVD-19 who had comorbidities upon confirmation of thediagnosis.

\section{CONCLUSIONS}

Patients with comorbidities should take all necessary precautions to avoid getting infected with SARSCoV-2, as they usually have the worst prognosis. There is a need for a global public health campaign to raise awareness, on reducing the burden of these comorbidity illnesses causing deaths in COVID-19-infected patients.

\section{ACKNOWLEDGEMENTS}

We would like to thank all of our colleagues and other personnel of National Institute of Preventive and Social Medicine (NIPSOM), Mugda Medical College (MuMC) for their constructive cooperation. In addition, we would like to thank all of our co-authors for their valuable contribution for this work. We also acknowledge all of those helping hands, as without their valuable contribution this work couldn't see the light of success.

\section{LIMITATIONS}

A main limitation was the self-reporting of comorbidities on admission. We did not approach patients to obtain additional history or biologic samples for laboratory measurement. Because of the rapid evolving outbreak globally, ongoing studies with the inclusion of more patients would be needed to increase the statistical power and lend support to subgroup analyses stratified by the specific comorbidities and their association with the risk of death.

\section{Declarations}

Funding: No funding.

Conflict of interest: No competing interests relevant to this study to disclose for all authors. Full forms submitted and on file for allauthors.

Ethical approval: All the procedures were conducted following the ethical guidelines of institution's ethical committee (IRB) at Mugda Medical College Hospital, Bangladesh (Memo No/MUMC/2020/617). The ethical standards as laid down in the 1964 Declaration of Helsinkiand its later amendments or comparable ethical standards will be followed whereverapplicable.

\section{REFERENCES}

1. Yang X, Yu Y, Xu J, et al.Clinicalcourseand outcomes of critically ill patients with SARS- CoV-2 pneumonia in Wuhan, China: a single-centered, retrospective, observational study. Lancet Respir Med 2020;8: 475-81.

2. Grasselli G, Zangrillo A, Zanella A, et al. Baseline characteristics and outcomes of 1591 patients infected with SARS-CoV-2 admitted to ICUs of the Lombardy Region, Italy. JAMA 2020 Apr.6. doi: 10.1001/jama. 2020.5394.

3. Bhatraju PK, Ghassemieh BJ, Nichols $\mathrm{M}$, et al. COVID-19 in critically ill patients in the Seattle region - case series. N Engl J Med 2020 Mar. 30, doi: 10.1056/NEJMoa2004500.

4. Richardson S, Hirsch JS, Narasinhan M, etal. Presenting characteristics, comorbidities, and outcomes among 5700 patients hospitalized with COVID-19 in the New York CityArea. JAMA 2020 Apr. 22, doi: 10.1001/ jama.2020.6775.

5. Lai CC, Shih TP, Ko WC, Tang HJ, Hsueh PR. Severe acute respiratory syndrome coronavirus 2 (SARSCoV-2) and coronavirus disease- 2019 (COVID-19): The epidemic and the challenges. In J Antimicrob 
Agents. 2020;55(3):105924. DOI:10.1016/j. ijantimicag. 2020.105924

6. Qiu H Tong Z Ma P et al., Intensive care during the coronavirus epidemic. Intensive Care Med. 2020; 46:576-578

7. ICU Care Management Challenges and Recommendations for COVID-19,Infectious Disease Advisor, access on: 19.07.2020 Available at:https:// www. infectious diseaseadvisor.com/home/ topics/covid19 /icu-care-management-challenges- and-recommendations-for-covid-19/

8. Docherty, A. B., Harrison, E. M., Green, C. A., Hardwick, H. E., Pius, R., Norman, L., Holden, K. A., Read, J. M., Dondelinger, F., Carson, G., Merson, L., Lee, J., Plotkin, D., Sigfrid, L., Halpin, S., Jackson, C., Gamble, C.,Horby,P.W., NguyenVan-Tam,J.S.,M. G. (2020). Features of 20133 UK patients in hospital with covid-19 using the ISARIC WHO Clinical Characterisation Protocol: Prospective observational cohort study. The BMJ, 369. https://doi.org/10.1136/bmj.m1985

9. Fei Zhou (2020) Clinical Course and Risk Factors for Mortality of Adult in Patients with COVID-19 in Wuhan, China: A Retrospective Cohort Study. J Med Stud Res 3:015.

10. Huang C, Wang Y, Li X, Ren L, Zhao J, Hu Y,ZhangL,FanG,XuJ,GuX,ChengZ,Yu T,XiaJ, WeiY, WuW, XieX,YinW,LiH, Liu M, Xiao Y, Gao H, Guo L, Xie J, Wang G, Jiang R, Gao Z, Jin Q, Wang J and CaoB. Clinical features of patients infectedwith 2019 novel coronavirus in Wuhan, China. Lancet, 2020; 395: 497-506.

11. Novel Corona Virus 2019 Update, World-O- Meter, access on,02.09.2020. Available at: https://www. worldometers.info/

12. Daily Live Updates of Corona Virus: Aljazeera Television, access on, 02.09.2020. Available at:https://www.aljazeera.com/news/2020/06/eu -bar-travellers-brazil-coronavirus-live-updates-20062 7002953075.html.

13. Coronavirus India Live Updates, The India Express, access on,02.09.2020. Available at: https://indianexpress.com/article/india/coronavirus-i ndia-news-live-updates-covid-19-tracker-corona-cases -in-india-today-update-lockdown-extension-state-wis e-latest-news-tamil-nadu-delhi-6479588/

14. Singh AK, Gupta R, Ghosh A, Misra A. Diabetes in COVID-19: prevalence, pathophysiology, prognosis, and practical considerations. Diabetes Metab Syndr Clin Res Rev. 2020;14(4):303 -10https: //reader. elsevier.com/reader/sd/pii/S18 71402120300631? token=9053C7A9DEA8F 9AD35620DE8A76E569 E800C744D2785B F1F3E13C425A07B78B480145 B9E04D94 BE41439983005F17A52

15. Hossain I, Mullick AR, Khan MH, Aktaruzzaman M, Rahman S, Tuhin SGN, et al. Impacts of Conventional Oxygen Therapy on COVID-19 Patient in Intensive Care Unit (ICU). JMedSci ClinRes. 2020;08(08):183-9.

16. Hossain I, Khan MH, Ahmad SA, Aktaruzzaman M, Tuhin SGN, Rahman S, et al. Characteristics of Inpatients' Fatality Due to Covid -19 Pandemic: Experience From Mugda Medical College and Hospital , Dhaka ,. World J Adv Heal care Res. 2020; 4(5):11-5.

17. Hossain I, Mullick AR, Khan MH, Ahmad SA, Rahman S, Aktaruzzaman M. Epidemiologyof Coronavirus Disease :Past, Present , Future Prospects and Its Journey Towards Bangladesh. Int Med J. 2020; 25(06):2517-29.

18. Zhao Q, Meng M, Kumar R, Wu Y, Huang J, et al. The impact of COPD and smoking history on the severity of COVID-19: a systemic review and meta-analysis. J Med Virol. 2020. 10.1002/jmv. 25889 [Accessed April 18, 2020,https://www. ncbi.nlm.nih.gov/pubmed/3229 3753].

19. YangJ, ZhengY, GouX, Pu K, Chen Z, Guo Q, Ji R, Wang $\mathrm{H}$, Wang Y, Zhou Y. Prevalence of comorbidities in the novel Wuhan coronavirus (COVID-19) infection: a systematic review and meta-analysis. Int J Infect Dis. 2020; S1201-9712 (20): 30136- 30133. doi:10.1016/j.ijid.2020.03.017.

20. Franki R. Comorbidities the rule in New York's COVID-19 deaths. Hospitalist. 2020; [Accessed June 1, 2020,https://www.the- hospitalist.org/hospitalist/ article/ 220457/coronavirus-updates/ comorbidities -rule-new- yorks-covid-19-deaths].

21. United Nations Department of Economicand Social Affairs Population Dynamics. World population prospects2019. AccessedApril6, 2020.https:// 
population. un.org/wpp/Graphs/ Demographic Profiles/ Pyramid/840

22. Chen Z, Peto R, Zhou M, et al; China Kadoorie Biobank (CKB) collaborative group. Contrasting male and female trendsin tobacco-attributed mortality in China: evidence from successive nationwide prospective cohort studies. Lancet. 2015; 386(10002):1447-1456. doi:10.1016/S0140- 6736 (15)00340-2

23. Institute for Health Metrics and Evaluation. GBD Compare/Viz Hub. Accessed April 6, 2020. https://vizhub.healthdata.org/gbd-compare/

24. Richardson S, Hirsch JS, Narasimhan M, et al. Presenting Characteristics,Comorbidities, and Outcomes Among 5700 Patients Hospitalized with COVID-19 in the New York City Area.JAMA. 2020; 323(20):2052- 2059. doi:10.1001/ jama.2020.6775

25. Li Q Guan X Wu P et al., Early transmission dynamics in Wuhan, China, of novel coronavirusinfected pneumonia. N Engl J Med. 2020; (published online Jan 29.) DOI:10.1056/NEJMoa20013168.

26. World Health Organization. Coronavirus disease (COVID-19) technical guidance: laboratory testing for 2019-nCoV inhumans. [cited 2020 Jan24]. Available at: https://www.who.int/ emergencies/ diseases/novel-coronavirus- 2019/technical-guidance /laboratory-guidance

27. Docherty, A. B., Harrison, E. M., Green, C. A., Hardwick, H. E., Pius, R., Norman, L., Holden, K. A., Read, J. M., Dondelinger, F., Carson, G., Merson, L., Lee, J., Plotkin, D., Sigfrid, L., Halpin, S., Jackson, C., Gamble, C.,Horby,P.W., NguyenVan-Tam,J.S.,M. G. (2020). Features of 20133 UK patients in hospital with covid-19 using the ISARIC WHO Clinical Characterisation Protocol: Prospective observational cohort study. The BMJ, 369.https://doi.org/10.1136/bmj.m1985

28. Huang C, Wang Y, Li X, et al. Clinical features of patients with 2019 novel coronavirus in Wuhan, China. Lancet 2020; 395:497-506. doi:10.1016/ S0140 -6736(20)30183-5

29. Chen N, Zhou M, Dong X, et al. Epidemiological and clinical characteristics of 99 cases of 2019 novel coronavirus pneumonia in Wuhan, China: a descriptive study. Lancet 2020; 395: 507-513. doi:10.1016/S0140-6736(20)30211-7 [PMC free article] [PubMed] [CrossRef] [Google Scholar]

30. Wang D, Hu B, Hu C, et al. Clinical characteristics of 138 hospitalized patients with 2019 novelcoronavirus-infected pneumonia in Wuhan, China. JAMA 2020; in press [https://doi.org/ 10.1001/jama.2020.1585]. doi:10.1001/jama.2020. 1585

31. Kui L, Fang YY, Deng Y, et al. Clinical characteristics of novel coronavirus cases in tertiary hospitals in Hubei Province. Chin Med J 2020; in press [https://doi.org/10.1097/CM9.00000000000 00744]. doi:10.1097/CM9.0000000000000744

32. $\mathrm{Xu} X \mathrm{XW}, \mathrm{Wu} \mathrm{XX}$, Jiang XG, et al. Clinical findings in a group of patients infected with the 2019 novel coronavirus (SARS-Cov-2) outside of Wuhan, China: retrospective case studies. BMJ 2020; 368: m606. doi:10.1136/bmj.m606

33. PlaczekHED,MadoffLC.Associationofage and comorbidity on 2009 influenza A pandemic H1N1related intensive care unit stay in Massachusetts. Am J Public Health 2014; 104: e118-e125. doi:10.2105/AJPH.2014.302197

34. Mauskopf J, Klesse M, Lee S, et al. The burden of influenza complications in different high-risk groups. J Med Economics 2013; 16: 264-277. doi:10. 3111/13696998.2012.752376

35. Shiley KT, Nadolski G, Mickus T, et al. Differences in the epidemiological characteristics and clinical outcomes of pandemic (H1N1) 2009 influenza, compared with seasonal influenza. Infect Control HospEpidemiol 2010; 31: 676-682. doi:10. 1086/653204

36. Martinez A, Soldevila N, Romeo-Tamarit A, et al. Risk factors associated with severe outcomes in adult hospitalized patients according to influenza type and subtype. PLoS One 2019; 14:e0210353.

37. Gutiérrez-González E, Cantero-Escribano JM, Redondo-Bravo L, et al. Effect of vaccination, comorbidities and age on mortality and severe disease associatedwith influenza during the season 2016-2017 in a Spanish tertiary hospital. J Infect Public Health 2019; 12: 486-491. doi: 10.1016/j.jiph.2018.11.011 
38. Booth CM, Matukas LM, Tomlinson GA, et al. Clinical features and short-term outcomes of 144 patients with SARS in the greater Toronto area. JAMA 2003; 289: 2801-2809. doi:10.1001/jama. 289.21. JOC30885

39. Alqahtani FY, Aleanizy FS, Ali Hadi Mohammed R, et al. Prevalence of comorbidities in cases of Middle East respiratory syndrome coronavirus: a retrospective study. Epidemiol Infect 2018; 5:1-5.

40. Badawi A, Ryoo SG. Prevalence of comorbidities in the Middle East respiratory syndrome coronavirus (MERS-CoV). Int J Infect Dis 2016; 49:129-133. doi: 10.1016/j.ijid.2016.06.015

41. Rahman A, Sarkar A. Risk factors for fatal Middle East Respiratory Syndrome coronavirus infections in Saudi Arabia: analysis of the WHO line list, 2013-2018. Am J Public Health 2019; 109: 1288-1293. doi:10. 2105/AJPH.2019.305186

42. Alanazi KH, Abedi GR, Midgley CM, et al. Diabetes mellitus, hypertension, and death among 32

patients with MERS-CoVinfection, Saudi Arabia. Emerg Infect Dis 2020; 26: 166-168. doi:10. 3201/eid2601.190952
43. Yang YM, Hsu CY, Lai CC, et al. Impact of comorbidity on fatality rate of patients with Middle East Respiratory Syndrome. Sci Rep 2017; 7:11307. doi:10.1038/s41598-017-10402-1

44. Garbati MA, Fagbo SF, Fang VJ, et al. A comparative study of clinical presentation and risk factors for adverse outcome in patients hospitalised with acute respiratory disease due to MERS coronavirus or other causes. PLoS One 2016; 11:e0165978. doi: 10.1371/journal.pone.0165978

45. Rivers CM, Majumder MS, Lofgren ET. Risks of death and severe disease in patients with Middle East Respiratory Syndrome coronavirus, 2012-2015. Am J Epidemiol 2016; 184: 460-464. doi:10.1093/aje/ kww013

46. Kulscar KA, Coleman CM, Beck S, et al. Comorbid diabetes results in immune dysregulation and enhanced disease severity following MERS-CoV infection. JCI Insight 2019; 20:e131774.

47. Matsuyama R, Nishiura H, Kutsuna S, et al. Clinical determinants of the severity of Middle East respiratory syndrome (MERS): a systematic review and meta-analysis. BMC Public Health 2016; 16: 1203. doi:10.1186/s12889-016-3881-4 